\title{
Correspondencia cervantina de D. Alberto Sánchez (II)
}

\author{
José CARlos De Torres*
}

Carta séptima: $28-V-1976$

Breve escrito para excusarse por qué abandonó Madrid con prisa tras asistir a las conferencias de la Fundación Universitaria Española en Madrid. Cuando José María se jubiló de su despacho y quehaceres fue cuando pudo atender al proyecto de la Asociación de Cervantistas.

Palma de Mallorca, 28 de mayo 1976.

Sr. D. Alberto Sánchez

Alcalá, 323

Madrid-27

Mi estimado amigo:

Apenas acabó su magnífico parlamento el Sr. Sainz Rodríguez, tuve que salir pitando para el aeropuerto para no perderme el avión de regreso a casa.

Sentí no poder agradecerle personalmente la «propaganda» que hizo Vd. de mí y lo halagado que me sentí por ello. Se lo digo ahora.

Entre el 13 y el 20, salvo contraorden, estaré en Escocia. Pienso ir a visitar a Mr. Riley en Edimburgo, a ver si hay suerte. Si quiere Vd. algo de él, pues sé que les une gran amistad, dígamelo sin reservas algunas. Tengo que ir hasta Inverness y, como es natural, voy a intentar la suerte con lo del monstruo.

Siempre a su disposición, afmo.,

Casasayas

* CSIC y Asociación de Cervantistas, Madrid. 


\section{Contestación del 2 de junio de 1976}

D. Alberto se refiere al viaje próximo de José María a Escocia. Escribe de la preparación del volumen XV de Anales Cervantinos y menciona la biblioteca de D. Miguel Bordoy, también coleccionista de objetos cervantinos (más bien lo segundo)

2 junio 1976

Sr. D. José M. ${ }^{a}$ Casasayas

Palma de Mallorca

Querido amigo:

Recibí su amable carta del 28 de mayo ppdo., que me apresuro a contestar ante la inminencia del viaje a Escocia que me anuncia. Buena envidia que me da, porque Escocia, de todos mis recorridos fuera de España, es de donde guardo más gratos recuerdos y no quisiera irme de este mundo sin volver por allí. Si viera usted al profesor Riley le saluda muy cordialmente de mi parte y le dice que aguardo nuevas colaboraciones suyas para Anales Cervantinos.

De momento estamos preparando ya el vol XV (la parte mía es la más atrasada). Tengo entre manos ahora mi contribución al homenaje del cervantista Moreno Báez y mi ponencia (ya enviado el resumen) para el I Congreso Internacional de la Picaresca: las dos de tema cervantino.

Le desea un viaje feliz y le saluda con todo afecto

Alberto

¿Estará Vd en Palma durante el mes de julio? Estoy estudiando la posibilidad de ver los libros de Bordoy...

Alberto

\section{Carta octava: 5-VI-1976}

Aparece el nombre de otro cervantista palmesano, D. Miguel Bordoy Cerdà, cuya colección de objetos relacionados con el mundo quijotesco y biblioteca conocí en 1977. Comenta su desagrado por el contenido de un libro publicado en Las Palmas de Gran Canaria debido a su contenido muy poco serio con un clásico como el Quijote.

Palma de Mallorca, 5 de junio 1976.

Sr. D. Alberto Sánchez

Alcalá, 323

Madrid

Mi querido amigo:

Respondo a la suya del día 2, que, como siempre, agradezco. 
Sí estaré, D.M., en julio en Palma. La familia veraneando en el chalet y yo yendo y viniendo. Me he tropezado de casualidad a Bordoy esta mañana, junto a los Juzgados, y hemos hablado de Vd. Dice que casi no se cree lo de su anunciada visita «porque hace cuarenta años (sic) que me lo viene repitiendo». Lo que he interpretado como una verdadera ilusión por parte de Bordoy (a la que tiene que sumar desde ahora la mía) de que, de verdad, nos haga Vd. este honor. A ver, pues, si esta vez dispone Vd. de unos días de vacaciones.

Acabo de dejar de las manos, porque no he tenido valor para leerlo íntegro, la obra de Pedro Perdomo Azopardo, La vida golfa de Don Quijote y Sancho, Bandama colección literaria, Las Palmas de Gran Canaria, 1975, Impreso por Breogán I.G.S.A., Torrejón de Ardoz (Madrid), 180x113, 221 $\mathrm{p}$ +hoja. Se lo recomiendo para que tenga Vd. ocasión de decir, en su estupenda Bibliografía de los A.C., que la influencia cervantina se ha ramificado tanto que hasta da ocasión a que con los nombres de don Quijote y de Sancho se cometan profanaciones tan estúpidas como la del librito en cuestión. ¿Por qué se toleran tamaños desafueros?

Ya le diré qué tal me ha ido en Escocia. Salgo, es de esperar, el día 13, domingo. Y me da una pereza como no puede Vd. imaginarse. Por mi gusto, aunque el ver cosas nuevas siempre me atrae, no saldría, empero, nunca de mi despacho. Me añoro al estar sin mi familia.

Siempre a su disposición, y atentamente

Casasayas

\section{Contestación manuscrita del 7 de octubre de 1976 (aniversario de la batalla de Lepanto)}

Le comunica la llegada del estudio del profesor Flores, si bien con retraso por huelga postal. Además de varios trabajos suyos, y del aplazamiento del viaje a Palma de Mallorca para conocer la biblioteca de Bordoy.

Madrid, 7 de octubre 1976

Sr. D. José M. ${ }^{a}$ Casasayas Truyols

Palma de Mallorca

Mi querido amigo::

Acabo de recibir por correo certificado su magnifico obsequio del libro de Flores estableciendo las variantes de la 1. ${ }^{\mathrm{a}}$ y 2. ${ }^{\mathrm{a}}$ edición del Quijote, Parte I, o más propiamente dicho, del Quijote de 1605, pues, como Vd. sabe muy bien, está dividido en cuatro partes, aunque el de 1615 aparezca como la 2. ${ }^{\text {a }}$ Parte. Desde que Vd me lo ofreció amablemente por teléfono lo esperaba, pero la huelga de carteros, que ha durado en Madrid quince días, a pesar de las noticias contradictorias de la Jefatura de Correos, han hecho que llegue a mis manos en esta fecha. De todas formas, llega a tiempo para ser incluido un comentario sobre el mismo en mi bibliografía cervantina con destino al tomo XV de Anales, demorada por los endémi- 
cos problemas administrativos del Consejo Superior de Investigaciones. Tendremos que darle a Vd la razón, una vez más, sobre la marcha de los organismos oficiales. Todavía no me han enviado pruebas del volumen que se prepara con las ponencias de la Jornadas Bibliográficas de la Fundación Universitaria Española, presenciadas por Vd en mayo último. Juntamente con mi aportación al I Congreso Internacional de la Picaresca, celebrado en Junio, y al Homenaje de la Universidad de Santiago al Prof. Moreno Báez, que remití el día 7 del mes pasado (y tengo acuse de recibo del 10), son en conjunto tres trabajillos de variado tema cervantino, que tengo ahora pendientes de su publicación. Tuve carta de Bordoy sobre mi proyectado viaje a Palma, que todavía no he podido realizar. Espero hacerlo en la primera ocasión propicia, pues mi condición de jefe único de familia me tiene más ligado de lo corriente.

Muy agradecido a su generoso envío, le envía cordiales saludos

Alberto Sánchez

\section{Carta novena: $13-X I-1976$}

José María plantea a D. Alberto su ayuda necesaria para consultar en la biblioteca del Instituto «Miguel de Cervantes» el fondo especial cervantino, que se guardaba en el despacho número 14. La bibliotecaria, Sonsoles Arangüena, le debía haber hablado del mismo, pero no tenía autorización para enseñar tales fondos a un lector. Además le pide ayuda para conseguir, o consultar si es posible, una fuente difícil de hallar. Sale a relucir la afición al ajedrez y el organizador de eventos que fue José María.

Palma de Mallorca, 13 nov. 1976.

Sr. D. Alberto Sánchez

Alcalá, 323

Madrid-27

Mi querido y nunca jamás tan añorado amigo:

Le escribo a vuela pluma, recién llegado de la ciudad que más se enorgullece de haber sido alabada por Cervantes, es decir Barcelona, no tanto para desahogar (y perdóneme que lo haga en $\mathrm{Vd}$.: es por la confianza que en Vd. tengo) el cabreamiento que llevo encima, como para pedirle si lo que no he conseguido en Barcelona puedo conseguirlo en Madrid.

Aprovechando que por la tarde de ayer tenía una reunión de trabajo con unos colegas míos, con duración de prácticamente dos o tres horas, me fui allí en el primer avión de la mañana para disponer de ésta libre de la forzada obligación abogacil y ocupada, empero, en la tarea de tomar unos datos de algunas obras sobre bibliografía cervantina que, a pesar de años de búsqueda, no he podido conseguir.

Y fueron tantos los inconvenientes, las trabas, etc., que me pusieron por delante que, convencido de que la proyectada huelga de las Comisiones 
Obreras (¿se dice así?) habíase entrado en la Biblioteca, renuncié a mi propósito, con un cabreo, repito y pido por ello perdón, que aún me dura.

$\mathrm{Y}$ pregunto, y ruego que me conteste con toda sinceridad: si voy un día a Madrid ¿podré a mis anchas y libremente consultar lo que me interesa de la sección cervantina? Me refiero a la librería del CSIC ¿Hay allí establecido servicio de fotocopias? Desde luego he de advertir que no me interesa consultar de momento, ninguna de las ediciones del siglo XVII: sólo quiero consultar algunos trabajos sobre bibliografía cervantina recientes, del siglo XX.

Más aún: Posiblemente Vd. tenga alguna de éstas, como de propiedad particular de Vd., en casa. ¿Habría entonces algún inconveniente en que, trasladado yo a Madrid, fuésemos juntos a un servicio de fotocopias cualquiera y allí fotocopiase lo que me interesa, aunque fuese la obra íntegra?

La Biblioteca Central de Barcelona no puede efectuar este servicio por dos motivos; $1 .^{\circ}$, se trata de obras de no reciente publicación (entre 1946 y 1961), y ello impide que los libros no puedan abrirse en su totalidad ( ¿y si uno quiere leerlos?, digo yo) ni pueden ser sometidos al calor (?) de la fotocopiadora; y $2 .^{\circ}$, se trata de libros sí recientes (menos de ochenta años) sobre los cuales existe prohibición, en virtud del derecho de propiedad intelectual, de reproducción... Solamente podrían ofrecerme la reproducción en microfilm, nunca bien asegurada, y a un precio carísimo, y aún de sólo alguna parte de la obra...

Ando desesperado tras el ensayo bibliográfico de Grismer, 1946, la primera parte (la segunda, publicada en 1962, ampliación de la primera, la tengo). Llevo escritas, desde hace unos años más de una docena de cartas a varios libreros de USA, y, o no recibo contestación, o no la encuentran.

La obra que publicó la Cámara del Libro, de Moscú, 1959, sobre bibliografía rusa de Cervantes, me cuesta también un sin fin de pesquisas. Últimamente ha escrito al presidente de la federación soviética de Ajedrez, con quien me une cierta amistad, y que es un hombre cultísimo, por ver si puede hacerse con un ejemplar para mí.

He renunciado ya, porque la paciencia siempre tiene un límite, a seguir buscando la obra de Areny y Roch, Lérida, 1948, sobre las ediciones ilustradas del Quijote. Puse influencias incluso con un íntimo amigo mío, que es ahora Corredor de Comercio establecido en Palma y que antes estuvo en Lérida, etc., etc. Algún día la ocasión me la pondrá en mis manos.

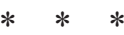

Estoy apurado-ísimo, de trabajo en todos los órdenes. Reina un desorden en mi despacho peor que el que ocasioné el baciyelmo en la venta. Se me amontonan los libros, se me retrasan causas por despachar y cartas por contestar y, encima, la apurada situación de la economía española no deja de hacer mella en la cuenta particular, y en la moral también, qué caramba, de uno.

Menos mal que la lectura del último quijotesco disparate le quita a uno el mal sabor del penúltimo. Si Dios me otorga tiempo y donaire suficientes, algún día voy a intentar probar que la esencia de la cultura literaria española no reside ni en el Mío Cid, ni en la Celestina, ni en Lazarillo, ni 
siquiera en el Quijote (por más que su proyección sea ya universal), sino en el Don Juan Tenorio, y no precisamente por «que largo me lo fiáis», sino por el «Cual gritan esos malditos...» aunque su griterío no coincida con la víspera de difuntos.

Un afectuosísimo abrazo de su buen admirador

Casasayas

\section{Contestación del 20 de noviembre de 1976}

Es importante destacar que además de la ayuda bibliográfica a Casasayas, como a otros profesores (así Zamora Vicente, Vicente Gaos, Juan Luis Alborg, etc.), D. Alberto le revela su satisfacción porque José María se identifica con «el tesón y la voluntad heroica al servicio desinteresado, y hasta notablemente dispendioso, de una noble causa cultural».

20-XI-1976

Sr. D. José M. ${ }^{\text {a }}$ Casasayas

Palma de Mallorca

Muy querido amigo:

Contesto casi a vuelta de correo a su estimada carta del 13 de Nov. en curso, llegada con algún retraso. Por si ésta tarda otro tanto, me decido a contestar en seguida, ante su apurado SOS bibliográfico. De las tres bibliografías que menciona, tengo dos (la de Grismer y la rusa) en mi biblioteca particular y pongo a su disposición para fotocopiar las páginas que le interesen. Me dice mi hija mayor que en el barrio de Argüelles, funcionan varios aparatos de fotocopias muy baratos (a 2'50 pts, e incluso a dos), con papel malo, claro está, muy frecuentados por los alumnos de la Universidad Complutense. En cuanto al libro de Areny, me va por la cabeza que lo pude consultar en la Sección Cervantina del CSIC (Medinaceli, 4, 2. ${ }^{\circ}$ ). Naturalmente, Vd. también podría hacerlo y yo mismo le presentaría a la bibliotecaria; pero creo que allí no tienen servicio de fotocopia. Quizá pudiera hacerse en la Biblioteca Central del CSIC (Serrano, 117), pero no estoy seguro de si allí tendrán ese libro. Se me ocurre comunicarle que nuestro común amigo Alberto Porqueras, profesor como ya sabe en Wisconsin, USA, es ilerdense o leridano, ha trabajado en la biblioteca particular de Areny y debe tener amistad con el veteranísimo cervantista y bibliófilo de la ciudad del Segre.

Veo que Vd. ha heredado del ingenioso hidalgo manchego el tesón y la voluntad heroica al servicio desinteresado - y hasta notablemente dispendioso - de una noble causa cultural. Si se decide a venir por aquí, avíseme previamente, porque no ignora $\mathrm{Vd}$. mis múltiples actividades y quiero atenderle en la medida de mis posibilidades. Por ejemplo, el próximo fin de semana, día 26 por la tarde, me traslado a Granada, para regresar el 28 por la noche.

Reciba un cordial abrazo de su buen amigo

Alberto S. 


\section{Carta décima: 17-XII-1976.}

Responde a un viaje suyo a Madrid, donde debió ya consultar fondos cervantinos nuestros y fotocopiarlos. Aparece mencionada la «Casa Frasquet», que ahora lleva uno de sus hijos. En el piso superior tuvo la biblioteca científica y bibliófila. La otra afición musical estaba en su casa: varios millares de CD de música clásica, con Wagner de manera muy especial.

Palma de Mallorca, 17 dic. 1976.

Sr. D. Alberto Sánchez

Madrid

Mi querido don Alberto:

Solamente, esta vez, para agradecerle su estimable compañía y valiosa cooperación durante mi última estancia en Madrid, y desearle felices Navidades, largas y tranquilas vacaciones, y buen comienzo $-\mathrm{y}$ mejor final- para 1977, y muchos etcéteras venturosos. Amén.

Casasayas

No escribí antes porque el trabajo me abruma. Llevo unos días pasando no más de tres o cuatro horas diarias en la casa. ¿Sabía Vd que jamás había encontrado tanta atención y eficiencia como la de la Srta. Sonsoles del Instituto «M de $\mathrm{C} »$ del CSIC?

Le repito el envío de unos turrones porque, aunque no me dijo nada acerca de ellos, estoy seguro de que gustaron. Sería el primer caso que no ocurriera así desde que Casa Frasquet (que ya existía en tiempos de Cervantes!) sirve a su clientela.

\section{Contestación manuscrita de 21 de diciembre de 1976}

Escribe D. Alberto agradecido por los presentes enviados a varias personas por Navidad; de las felicitaciones recibidas; de pruebas de imprenta; del conocimiento bibliográfico por los comentarios de Sonsoles al pedirle fondos de nuestra biblioteca, y de las jornadas cervantinas proyectadas por Criado de Val para 1977, preparatorias del congreso sobre Cervantes, a celebrar en Madrid durante 1978.

21-XII-76

Sr. D. José M. ${ }^{a}$ Casasayas Truyols

Palma de Mallorca

Mi querido amigo:

Ayer llegó su nuevo, y generoso hasta la prodigalidad, mensaje navideño, antes de que yo le hubiera escrito acerca de los suculentos turrones, que 
acompañaron a su memorable visita del 25 de noviembre próximo pasado. Solamente la dulcísima Dulcinea como la llama D. Quijote repetidamente (1. ${ }^{\mathrm{a}}, \mathrm{XXV}$ y LII) podría competir con la dulzura y exquisitez de la firma Casasayas, Frasquet, Ltd. Quedo muy agradecido a sus repetidas atenciones que verdaderamente me abruman: non sum dignus...

Este final de semestre, rodeado de exámenes y ejercicios por todas partes, he tenido que faltar a los deberes de la amistad. Liberado ya de las clases, hasta el 10 de enero, puedo ya atender a la correspondencia y acelerar las lecturas cervantinas atrasadas. Hoy mismo he recibido «Christmas» de tres cervantistas: dos profesores americanos (Allen, de la Florida, y Stanislav Zimic, de Texas) y de nuestro común amigo Bordoy, con una tarjeta muy ingeniosa, en la que fácilmente se salva la errata de la numeración de los dos capítulos del Quijote $\left(2{ }^{\mathrm{a}} \mathrm{P}\right)$ aludidos. Se ha felicitado por la «peregrina» idea que le ha impulsado a imprimir estas felicitaciones navideñas. Esta mañana he saludado en el CSIC a la Srta. Sonsoles, que está asombrada del dominio de la bibliografía cervantina por Vd. Y, a propósito: la semana anterior al referéndum, corregí las pruebas de imprenta de mi aportación a las Jornadas Bibliográficas de la Fundación Universitaria, que presenció Vd. Parece que saldrá el volumen a comienzos del año próximo: ya le enviaré una separata dedicada, en modesta retribución y anticipo de lo que deben a Vd. estas páginas. Esta tarde me ha telefoneado Criado de Val, comunicándome su proyecto para la reunión bibliográfica cervantina de Palma, el próximo año como preparación del Congreso, que se celebrará en Madrid el 1978.

El día 30 voy con mis hijas a Cheste para pasar allí Nochevieja y los Reyes. Necesito cambio de aires. Reciba un cordial abrazo de su buen amigo.

Alberto Sánchez.

\section{Carta undécima: $17-1-1977$}

Contiene noticias de la convocatoria de un Congreso internacional en Madrid, cuyo director fue el Dr. Criado de Val del Consejo. Lo patrocinó el Instituto, cuya directora era la Dra. Conchita Casado. Alude la carta igualmente a la afición bibliófila de José María y su carácter resuelto, su utopía una vez más, para controlar la bibliografía cervantina: «[...] dentro de febrero acabaré mi ensayo o estudio sobre cómo tiene que ser la bibliografía cervantina».

Palma de Mallorca, 17 enero 1977.

Sr. D. Alberto Sánchez

Alcalá, 323

Madrid-27

Mi buen amigo don Alberto:

Recibí su atentísima carta del 21-XII-76 con la felicitación navideña adjunta, estuve en Madrid el pasado día 13..., y yo, sin embargo, sin con- 
testarle ni llamarle siquiera por teléfono. Los apuros en mis «trabajaciones» navideñas y el apurado tiempo de medio día en Madrid, no me permitieron cumplir debidamente con Vd. Apenas tuve tiempo el día 13 de una visita rápida al Instituto, para encargar unas fotocopias a la Srta Sonsoles.

Espero con ilusión sus artículos cervantinos, que en viniendo de quien vienen tendrán que ser interesantes a la fuerza. Ya verá Vd. cómo, si Dios ayuda (y mucho me temo que tendrá que ayudar mucho), en más de una ocasión le apremiaré para aportaciones a la publicación que, sea como sea, tiene que llegar a ser una realidad algún día.

Quisiera comentar, para deshacer equívocos, la circunstancia de que el Sr. Criado de Val (a quién no conozco más que por sus excelentes publicaciones) le hablara a Vd. de la reunión previa en Palma de Mca del comité organizador del Congreso Cervantino de Madrid-1978. Ocurrió, en síntesis, que habiéndome enterado de este Congreso por carta de la Srta Sonsoles prometiéndome un programa (visto mi interés por lo de Cervantes), yo le contesté diciendo que ya en enero de 1976 le había sugerido a Vd la conveniencia de este Congreso (si bien con orientación marcadamente bibliográfica) y que hasta me había brindado a mantener una reunión previa en Palma de Mca para tranquilidad y buen trabajar de los organizadores, y que, finalmente, este ofrecimiento se mantenía en la actualidad y lo trasladaba a favor del comité (cuya composición yo ignoraba totalmente al escribir a la Srta Sonsoles). La idea parece que agradó a la eficiente bibliotecaria del Instituto, debió comentarla con los del comité organizador (el Sr. Criado de Val creo que es el capitoste), etc., etc.

He explicado esta circunstancia porque en ningún momento quisiera que creyera $\mathrm{Vd}$ que yo había tramado algo cervantino a espaldas de $\mathrm{Vd}$, y menos algo referente a este Congreso. Pero ¿por qué no me lo dijo Vd. cuando estuvimos juntos hace algo más de un mes?

Y bien, y ya que se ha hablado de ello, debo acabar este comentario reiterando:

primero, que mi oferta sigue en pie, para cuando y por el tiempo que necesiten Vds. para esta reunión previa; y

segundo, que mi intervención en tal asunto es total y absolutamente desinteresada.

Quiero decir con esto último (y es preciso recalcarlo, y así espero que se lo diga al Sr. Criado de Val, a quien, si Vd. lo cree conveniente, le puedo escribir directamente, para evitar malas interpretaciones) que esta invitación mía no es a cambio de ningún trato preferente para mí, ni de ninguna intervención ni influencia mías en sus decisiones o deliberaciones, ni de — siquiera - un pase de favor para las sesiones — en su día - del congreso. Creo que está claro que no pido nada a cambio y que me doy por satisfecho y bien pagado con que Vds estén a gusto en Palma y puedan trabajar tranquilamente sin los impedimentos cuotidianos de sus respectivas oficinas. Quiero hacer hincapié en esta consideración para evitar cualquier recelo por parte de Vds los del comité, y le agradecería que así se lo comunicara a los demás, si hablan de ello.

$\mathrm{Y}$ pasamos a otros asuntos.

Le supongo conocedor del artículo aparecido en ABC de Madrid, 2 de enero 77, firmado por Enrique Laborde e intitulado «En búsqueda por París. Manuscritos, incunables y libros raros». No es, como quiere dar a entender 
el articulista (oh, estos periodistas!), una búsqueda por la librería del Sr. Lardanchet, sino por el catálogo que ha publicado la Librairie Lardanchet, de Paris-Lyon, poniendo en venta la biblioteca de «J.D.» (así de anónimo) que contiene unas preciosas referencias, no solo cervantinas, como, por ejemplo, la edición de las Novelas ejemplares de Milán - 1615- Bidelo y la del Persiles de París - 1617- Richer, ambas en castellano, y de varios documentos referentes a las ejecutorias de nobleza de la familia de los Salazar de Esquivias y de otro pariente de Cervantes. Pero estamos en época de economía y hay que esperar mejores tiempos. El artículo, que es muy vulgar en sí, contiene varias inexactitudes (oh, otra vez, los periodistas!), que le vienen del mismo catálogo, como por ejemplo la de que de la edición del Quijote en italiano, de Venetia - 1622- Andrea Baba (ed. princeps italiana), sumamente rara, no existe en España otro ejemplar más que el de la Biblioteca de Cataluña; pues yo la tengo en mi biblioteca, encuadernado en pergamino de la época, completa y que es una delicia. ¿Por qué, me pregunto siempre, salen tantas noticias en los periódicos sin la más mínima documentación?

Ha llegado a mis manos (jamás ocurriera tal, y me hubiera evitado una indignación) la obra de Enrique Ruiz-Fornells Las concordancias de El Ingenioso Hidalgo Don Quijote de la Mancha, de Ediciones Cultura Hispánica, Madrid, 1976, tomo primero aún. También le supongo enterado de ello, y si no, le sugiero que se entere pues bien valdrá un buen comentario en los Anales Cervantinos. Mi reacción ante este mamotreto (y atención, que se trata de tomo I que contiene sólo las palabras empezadas por la letra A; lo que supone varios tomos más) ha sido confirmarme en la idea de que es preciso adelantar hasta donde pueda una publicación cervantina que ponga coto a tanto desatino como se está cometiendo contra Cervantes. Ya entreveo su comentario: una revista que sea una quijotada más! Pues si es preciso, sí, con tal de acabar con las impertinentes caballerías actuales.

$\mathrm{Si}$ la divina providencia me concede un poco de tranquilidad (Santo Dios y cuántos quebraderos de cabeza tengo a menudo!) dentro de febrero acabaré mi ensayo o estudio sobre cómo tiene que ser la bibliografía cervantina. Contiene una parte histórico-bibliográfica (bibliografía de bibliografías, detalladamente) y otra parte esquema estructural, índices de clasificación analítica, forma de llevar la empresa, etc., etc.

Tengo que volver a Madrid a finales de mes, pero lo retrasaré hasta el próximo. Si no es molestia le llamaré por teléfono.

Un afectuoso abrazo de su buen amigo 


\section{Contestación de 23 de enero de 1977}

Le explica cómo fue la resolución para decidir el congreso cervantino de 1978 con el prof. Criado de Val. Y como es frecuente en la correspondencia de D. Alberto, le habla de varias publicaciones recientes, entre ellas su edición del Quijote en la editorial Noguer.

Sr. D. José M. ${ }^{a}$ Casasayas Truyols

Palma de Mallorca

Mi querido amigo:

Recibí su muy afectuosa carta del 17 , rodeado de los papeles y trabajos, ya en su fase final de ordenación, que han de constituir el vol. XV de Anales Cervantinos.

Por supuesto, no existe ningún equívoco ni problema en torno a la preparación del Congreso Cervantino que se ha de celebrar en Madrid el 1978. Durante las sesiones del Congreso de la Picaresca del pasado mes de junio, se me acercó una mañana Criado de Val y me comunicó el proyecto de dedicar a Cervantes, o al Teatro Español del Siglo de Oro, la siguiente reunión, dos años después. Naturalmente yo le aconsejé levantar la bandera de Cervantes, como la más acreditada internacionalmente en los estudios literarios; aunque pensaba asistir de todas formas si se elegía el tema del teatro, pero en tal caso mi ponencia versaría acerca del teatro cervantino, en algún tema particular. Reunido el comité, del que yo no formo parte, resolvieron convocar el Congreso cervantino. En efecto, con fecha 20 de octubre, el Patronato "Arcipreste de Hita», del que es alma Criado de Val, promotor y organizador incansable de todo esto, me remitió la convocatoria y proyecto de temario, al que contesté el 16 de noviembre con algunas indicaciones para ampliación sobre bibliografía cervantina. Luego tuve ocasión de hablar con el propio Criado de Val y con la Srta. Sonsoles, eficaz colaboradora de estas empresas culturales. Si no le dije a Vd. nada es porque se me pasó entre otras atenciones, o quizá porque esperaba la redacción definitiva del temario, según las nuevas sugestiones apuntadas.

No leí el artículo que Vd. me indica del ABC del día 2 (andaba yo por Cheste en esas fechas) ni he podido consultar todavía lo de Ruiz Fornells, aunque de este profesor ya tenía yo noticias por su colaboración con Anales; de todas formas, no soy muy amigo de las estadísticas «mecánicas» aplicadas a las obras de arte literarias. En cambio, sí he pedido la adquisición a la Srta. Sonsoles, para la Biblioteca, del nuevo libro de Avalle- Arce, Don Quijote como forma de vida, o algo así, que acaba de salir en Castalia, bajo el patrocinio de la Fundación Juan March. También me ha llegado estos días, aunque solamente 4 ejs, por lo que no puedo ofrecérselo, mi Quijote de la Ed. Noguer, de Barcelona.

Reciba un afectuoso abrazo de su buen amigo 


\section{Carta duodécima: 3-II-1977.}

Breve escrito donde se determina conocer al profesor Criado de Val, además de fijar las fechas para las jornadas cervantinas en Palma, preparatorias del congreso internacional en 1978. D. Alberto había publicado una edición del Quijote en la editorial Noguer (septiembre del año anterior, de donde se deduce que habían hablado ya de ella).

Palma de Mallorca, 3 febrero 1977.

Sr. D. Alberto Sánchez

Alcalá, 323

Madrid-27

Mi querido don Alberto:

Sólo cuatro palabras para acusar recibo de la suya del 23 de enero, decirle que quedo enterado de que no hay segundas intenciones en lo de mi propuesta cervantina y anunciarle al mismo respecto (aunque le supongo ya enterado) de que parece ser que va por buen camino mi propuesta; pues acabo de recibir carta del Sr. Criado de Val en la que, con unas muestras de deferencia hacia mí que estoy bien seguro de no merecer, hasta me sugiere las fechas de la segunda semana de mayo para la reunión previa en Palma de Mallorca.

Por mí, encantado, y me alegro de todo corazón. Escribo hoy mismo al Sr. Criado de Val. Salvo pequeñas temporadas al año (Navidad, Semana Santa, y unas pocas más), gracias a Dios el tiempo me lo dispongo yo mismo. De manera que Vds. son los que mandan.

De todas formas, entre el 14 y 19 del presente mes deberé pasar uno o dos días en Madrid para otros asuntos profesionales, y ya me pondré en contacto con Vd. y con el señor Criado de Val. Así se lo digo a este último en mi carta. Y ya que están de moda las «cenas políticas», ¿por qué no implantamos nosotros las «cenas culturales»? Posiblemente, además de ser más beneficiosas, también resultarán mucho más simpáticas. Todo sería empezar, y ya vería Vd. el éxito que tendríamos.

No se preocupe Vd. por su edición del Quijote. Desde que me dijo Vd. que estaba en la editorial Noguer está pedido por mí. Lo que ocurre es que en las librerías de Palma no lo tienen aún. Ya llegará.

Hace unos días que apenas veo a Cervantes. Me los paso levantando planos y proyectos para parcelar unos terrenos paradisíacos (tanto que hasta los trapenses, cuando estuvieron en Mallorca, se instalaron allí) que adquirí hace unos años: tengo que ir preparando fondos para mis proyectos bibliográficos cervantinos...!

Hasta pronto, pues, y en Madrid. Siempre atto. afmo., etc., etc.

Casasayas

No hay respuesta. 


\section{Carta decimotercera: 8-III-1977.}

Consecuencia de la cena celebrada en «Sixto Gran Mesón», José María y D. Alberto han decidido tutearse. Comienzan los comentarios surgidos de la atenta lectura del Quijote para verterlo al mallorquín, empresa que resultó muy trabajosa y de varios años. La dejó concluida en su ordenador, que requirió a su fallecimiento el trabajo duro de Alicia Villar y su hijo Lluís para su publicación en el año 2005.

Palma de Mallorca, 8 marzo 1977.

\section{Sr. D. Alberto Sánchez}

Alcalá, 323

Madrid-27

Mi estimadísimo amigo:

Me perdonarás el que, olvidándome del respeto que tu ciencia cervantina y tu personalidad se merecen, me vaya tras el recuerdo de aquella estupenda cena copeada de mediados de febrero en Madrid, al final de la cual se impuso («o tempora, o mores») el tuteo como norma universal de conducta. Con tu permiso, pues, continúo.

La copia de la carta que dirijo a Criado de Val, como jefe del grupo, me excusa de todo otro comentario. A ella me remito para que tú también digas la tuya al respecto.

Hoy he recibido la visita de Miguel Bordoy, que me la ha leído la tuya del mes de febrero, pero que dice recibida ayer. Ya ves, por lo que digo a Criado de Val, que está entusiasmado con la reunión cervantina en Palma.

¿Cómo van tus ojos? Estoy ansioso por tener noticias, y espero de todo corazón que sean buenas.

He trabajado poco en Cervantes estas últimas semanas porque todo el tiempo se me ha ido detrás de infinitos y dispares problemas de despacho, propios y ajenos, que no le dejan vivir a uno, o por lo menos vivir como uno quisiera. Por las noches, ya en casa, mientras los demás se aburren, porque hay que decirlo así, delante del televisor, yo continúo con la traducción del Quijote al mallorquín, siguiendo, ordenando y mejorando la que en 1904, creo, publicara el cura de Felanitx Ildefonso Rullán. Veremos qué sale al final, si es que no me ocurra otro tanto como al pintor Orbaneja.

Esta lectura atenta del Quijote, como no había realizado en ninguna otra ocasión (la lectura en plan de querer traducir, que no «traicionar», tiene que ser muy profunda), ha despertado en mí una serie de consideraciones que pueden arrojar alguna luz (si es que no confunden más) sobre la atención que puso Cervantes, el cuidado que tuvo, etc., respecto a la forma con que quería expresar, no ya su pensamiento interno, sino más bien (y en esto es en lo que más he reparado) en simples detalles de apariencia formal, pero que, juntos, pueden revelar algo de su carácter. ¿Se ha fijado alguien, por ejemplo, en la de veces que usa el sistema de recalcar un imperativo ético o moral bajo la forma de un «de ser, y es» (el verbo ser, puesto aquí como ejemplo), que emplea tan a menudo? Expresiones parecidas a éstas se ven en infinitos pasajes, siempre en boca de don Quijote, «pues con saber, 
como sé, que», «debe ser, y es, propio de caballeros», «debe hacer, y hace, honor a», etc. ¿Es ello una querencia especial de Cervantes, vicio o manía de dicción, o una intención determinada para caracterizar al personaje, aquí don Quijote, en boca de quien siempre la usa?

Otra cuestión. ¿Se ha reparado por alguien en cómo reparte Cervantes, hablando siempre don Quijote, claro, los beneficios de la andante caballería respecto a las viudas, doncellas, huérfanos o menesterosos? Creo observar unos matices al respecto que apoyarían más la ironía con que escribía Cervantes. La ironía, como fondo de su pensamiento, y el cuidado que ponía en matizar sus intenciones, como forma externa.

No sé si me expreso con la debida exactitud. Para escribir la presente y una docena de cartas más he tenido que robar tiempo a la noche y he quedado en mi despacho. Está a punto de amanecer y si no echo una cabezadita en el sofá no habrá quién resista dentro de unas horas el prosaico tira y afloja de los comerciantes y de los leguleyos de nuestros anticuados tribunales curialescos.

Estoy acabando el último libro de Avalle Arce, siempre interesante por ser suyo, y escrito con una vivacidad y simpatía hacia el lector que lo hace más leíble que una novela de Simenon, dicho sea «sine animo offendendi», no faltaba más.

Y buenas noches, o mejor buenos días porque ya el rubicundo Apolo etc. etc., y espero noticias de todos vosotros. Amén.

Casasayas

\section{Contestación de 12 de marzo de 1977}

D. Alberto comenta brevemente sobre la próxima reunión cervantina en Palma de Mallorca; su estado de salud; sobre una reciente publicación y le responde a José María acerca de fórmulas o perífrasis verbales de obligación en el Quijote.

Sr. D. José M. Casasayas Truyols

Palma de Mallorca

Mi querido amigo:

He recibido tu afable carta del 8 , acompañada de la copia de la remitida a Manolo Criado de Val, con los naturales apremios para fijar los últimos detalles de nuestra proyectada reunión primaveral en la Isla de la Calma. La ínsula Maiórica de los romanos, que bien podemos convertir en esos días en la insula cervantina soñada.

En cuanto a mi problema personal de la vista, por el que tan solícita y amablemente te interesas, te diré que anteayer, día 10, fui al oftalmólogo, que examinó con toda atención la marcha de la dolencia en los dos ojos. Mi preocupación seria consistía en consultarle si era posible llegar al final de curso con mis alumnos extranjeros, entre el 10 y el 20 de mayo, antes de operarme y sin quedarme «a oscuras». Parece ser que la segunda catarata es 
todavía incipiente, aunque la neblina alarmante que se puso ante mi visión a finales de enero y comienzos de febrero, me estorbe un tanto la lectura del periódico y de algún tipo de impresos y manuscritos. El oculista me ha recetado unas gotas para alivio de esta situación y ha dispuesto que vuelva el diez de mayo próximo para nuevo reconocimiento, en el que dictaminará si debo operarme antes del verano o debemos esperar varios meses todavía.

Antes de esa fecha tengo que consultar, además, a mi médico general, que me vigila la hipertensión arterial. Todo esto son alifafes, más de la edad que del oficio, siempre molestos y perturbadores. Aunque a mal tiempo buena cara; créeme que no he faltado a ni una sola de mis obligaciones en todo el curso. Veremos si puedo decir lo mismo en adelante.

Esta semana, me han obsequiado de la Fundación March con el nuevo libro del amigo en Cervantes, Avalle- Arce, Don Quijote como forma de $v i d a$, que supongo es al que te refieres en la tuya. Lo estoy leyendo y me parece excelente. Con el retraso de la administración para dar luz verde al tomo XV de Anales, es posible que me dé tiempo para incluirlo en mi Bibliografía comentada, lo mismo que el de Cesáreo Bandera.

En cuanto a las fórmulas o perífrasis verbales de obligación que me señalas en el Quijote, no recuerdo en este instante si en la Gramática y vocabulario cervantino de Cejador, o en la edición del Quijote, del P. Rufo Mendizábal, que estudiaron la sintaxis de nuestro primer libro, se detuvieron en este aspecto. Por mi parte, veo mucha parodia irónica de fórmulas cristalizadas de lenguaje en el Quijote. Pienso ahora en el secularmente repetido - con poca gracia redactora - «fallamos que debemos condenar y condenamos» o en las muletillas mercantiles (en letras de cambio, pagarés, etc.) burlescamente recordadas o aludidas por Cervantes en "esta primera de pollinos» librada por Don Quijote a Sancho en Sierra Morena (1. ${ }^{\text {a }}$ P., c.XXV). Ya señaló un eco de la prosa curialesca López Estrada en el «de cuyo nombre no quiero acordarme...» del comienzo.

Un buen abrazo de tu buen amigo

Alberto S.

\section{Carta decimocuarta: 6-V-1977.}

Escrito muy angustiado de José María a Marta Sánchez para que haga lo imposible para venir a Palma con su padre. Le remite el programa de la «I Semana de Estudios Cervantinos». Contiene además un programa de la convocatoria del «I Congreso internacional sobre Cervantes».

Palma de Mallorca, 6 mayo 1977.

Srta. Hija de don Alberto Sánchez

Alcalá, 323

Madrid-27

Apreciada señorita:

Acabo de enterarme por teléfono y desde el CSIC de que el padre de Vd parece suspender definitivamente y por causa de fuerza mayor su visita a Palma con ocasión de la I Semana de Estudios Cervantinos. 
Aparte de la malaventurada, pero que Dios quiera con final feliz, circunstancia que afecta a la vista de su padre, no sé qué otras, más humanas, hayan podido concurrir para que tan fatalmente coincidieran las fechas de esta Semana con la inspección médica. Ni me adentraré en averiguarlo, porque el juego político, ni aún a este simple y modesto nivel, tiene cabida en mi modo de ser. Prefiero, pues, creer que ha sido una desgraciada combinación de la que nadie debe ser culpado.

Pero lo que me cae tan a contrapelo que ni aún ahora puedo admitirlo es que la principal, en todos los aspectos de prioridad (cronológica y por méritos propios), de las «dramatis personae» que van a protagonizar esta I Semana, es decir, su señor padre y admirado amigo mío, no esté presente en carne mortal (en espíritu, claro, siempre) en ninguna de las sesiones.

Sé que el día 10, a las 5 de la tarde, tiene que cumplir su padre con la imprescindible visita al médico. Que Dios le depare suerte, se lo digo de todo corazón. Pero, aparte de ello, insisto también: ¿Por qué no cogen Vd. y su padre el avión del día 11 y se vienen a descansar los días que quieran a Palma? Aquí serán tratados a cuerpo de rey, no lo dude. Ahora que hay presupuesto para estancia y desplazamiento, ¿por qué despreciarlo, máxime cuando la colaboración de su padre nos es tan imprescindible? No creo (un oftalmólogo amigo mío así me lo ha dicho) que un simple desplazamiento en avión pueda perjudicarle. Posiblemente, incluso, unos días de descanso le sentarían bien.

Hace unos días le dije todo a su padre de Vd. por teléfono. Hoy me aventuro a escribírselo de Vd. porque no me atrevo, si vuelvo a llamar directamente a su padre, a ser causa de rememorarle el pesar que debe sentir al no poder estar con nosotros. Y añado, y perdóneme la confianza que me tomo con Vd., que si bien es cierto que mi insistencia tiene un cierto matiz egoísta, por lo necesaria que es la presencia de su padre, no es menos cierto también que tiene un gran fondo de generosidad por mi parte, por lo mucho que le aprecio y le admiro, a él y a labor que ha venido realizando hasta ahora.

Espero haberle convencido. Y no digo más.

Afmo.

José M. ${ }^{a}$ Casasayas

PS. 1. Incluyo varios ejemplares del folleto-programa de esta primera semana.

2. Cuando se decidan venir (ya lo doy por cierto), llámeme a cualquiera de los teléfonos abajo indicados, que son de mi despacho, o también al 21.63.36 (que también es de mi despacho pero tan secreto que no figura en el listín), o, en último término, al de mi domicilio (sólo hora de comida y por la noche), que es el 22.35.27. 


\section{Carta decimoquinta: 8-XI-1977.}

Le pide ayuda bibliográfica y le insta, junto a Luciano García Lorenzo, para que vayan a Palma.

Palma de Mallorca, 8 noviembre 1977.

Sr. D. Alberto Sánchez

Alcalá, 323

Madrid-27

Mi querido Alberto:

¿Tienes tú idea de dónde y cómo podría adquirir, si no un ejemplar original, sí por lo menos una fotocopia del artículo que describo a continuación?

a) Conforme leo en «Bulletin Hispanique», LXXII-3/4, 1970, pp. 420-429 (donde hay reseña de Alexandre Zviguilsky):

N.I. Balachov, «Cervantés et les études modernes en Occident», Izvestia de 1'Académie des Sciences de 1' U. R.S.S., série de littérature et de langue, XXV, n. ${ }^{\circ} 6$ (novembre-décembre 1966), pp. 469-480.

b) Conforme leo en «Cervantes y la Literatura mundial», Editorial Nauka, Moscú 1969, p. 282 (y veremos qué tal me sale escribir en ruso, del que no tengo ni p... idea):

Валатов Н. И. Сегвантес и современная наука На Западе.«Иэв. АНССР». Серия лит-ры и яэ. 1966, т. 25, вьп. 6, с. 469-480.

Sin contar el fin de semana (12-13), solamente te quedan ya dos ocasiones para venir a Mallorca en compañía del común amigo Luciano. Te lo recuerdo porque no quiero que por mí se quede. Es más: porque tengo verdadera ilusión de veros aquí. Claro que siempre podéis venir en diciembre, después de tu ida a New York, o cuando queráis, que aquí seréis bien recibidos. Pero en diciembre yo no podré atenderos como merecéis y pasadas las fiestas de Navidad y Año Nuevo me parece ya muy lejano.

Estoy cansado, verdaderamente cansado, del trabajo vulgar y cotidiano del despacho, ramplón, rutinario, mísero en cuanto es exponente de infinitas flaquezas humanas, y que, encima, no me da tiempo para dedicarme a lo que yo querría. Pasado mañana salgo para Menorca con mi mujer, para ver de distraerme un poco. Aunque presiento que me llevaré conmigo el paquete de «maldecaps» que me agobia en estos momentos.

Escribo también a Luciano con referencia a una cita que me dio de palabra, mientras cenábamos en Alcalá.

Un cariñoso abrazo

Casasayas 


\section{Contestación de 17 de noviembre de 1977}

Comienza D. Alberto el escrito comentando la falta de tiempo para cumplir sus proyectos, y después se refiere a la consulta de José María sobre un trabajo del profesor ruso Balashov, que da lugar al conocimiento de la ortografía de la lengua rusa, así como a tratar de otros dos trabajos de los hispanistas Paolo Cherchi y Jean Canavaggio.

17-XI-77

Sr. D. José M. ${ }^{\text {a }}$ Casasayas Truyols

Palma de Mallorca

Mi querido amigo:

Recibí tu amable carta del 8 y si he retrasado un poco la respuesta, ha sido por si podía anunciarte mi visita para este fin de semana. Casi estaba ya decidido, cuando llegó la invitación para el discurso de la RAE de mi viejo amigo Terán, que ingresa el 20. Hablé con Luciano, que tampoco podía trasladarse ni este domingo, ni el siguiente. Hemos convenido, por tanto, en dejarlo para la primavera, marzo o abril.

La verdad es que está uno atrapado y no puede disponer ni aun de su tiempo libre. Los fines de semana anteriores los he dedicado a escribir mi próxima conferencia (la de New York), cuyo original he de dejarles allí para su publicación. Por cierto, ¿has abandonado tu proyecto de dar el salto?

En cuanto a tu consulta, sobre el artículo de Balashov (no ch=Y), lo tienes ya, pues te fotocopiaste mi ejemplar de Cervantes y la Lit. ${ }^{a}$ Mundial, págs. 7-37 (Por cierto que a mí me cita dos veces (págs. 12 y 20) a propósito del cervantismo de M. Pelayo. Me llena de admiración que puedas escribir a máquina en alfabeto cirílico; por cierto que no has hecho más que una errata: al nombre de Cervantes, le has puesto una $\mathrm{g}^{\mathrm{r}}$ rusa, en vez de la $\mathrm{r}$ $(\rho)$. Enhorabuena. Pero está claro que tú sabes más ruso del que declaras. Te advierto que no soy delegado, ni de hacienda ni de la CCCP (son las letras ruso-cirílicas de las que dispongo en mi Hispano Olivetti).

Se han recibido en el Consejo, remitidos por el autor, unos Capitoli di critica cervantina (1605-1789), de Paolo Cherchi (Roma, Bulzoni Editore 1977, 213 págs.), de contenido más que nada bibliográfico; los leeré despacio cuando regrese de los USA. Por mi parte, acabo de recibir una tirada aparte de Jean Canavaggio, «Le décor sylvestre de "la casa de los celos": mise en scène et symboles», publicado en los Mélanges... Aubrun (París, Ed. Hispanique: 1975). Parece que es un avance del libro Cervantès dramaturge: un théâtre à naître, que me anuncia para el mes próximo y me interesa mucho, porque el teatro de Cervantes es lo menos estudiado particularmente de toda su obra.

Hombre de plural actividad, se te nota en tu carta algo del cansancio que han dado en llamar stress, Cuídate, que el cervantismo confía en ti, como en uno de sus más entusiastas paladines.

Recibe un fuerte abrazo de tu buen amigo

Alberto S. 


\section{Carta decimosexta: 23-XI-1977}

Le agradece su ayuda bibliográfica y lamenta que pospongan él y Luciano el viaje a Palma. Vuelve a salir la afición a jugar al ajedrez. Le informa del encuentro con Vicente Gaos en Valencia. De D. Vicente hay varias cartas en la correspondencia de D. Alberto para consultarle bibliografía para su edición del Quijote.

Palma de Mallorca, 23 nov. 1977.

Sr. D. Alberto Sánchez

Alcalá, 323, 4. ${ }^{\circ}, \mathrm{A}$

Madrid-27

Mi querido amigo:

Te juro que de ruso no tengo ni 3,141592.. (=número $\pi$. que se lee pi, o sea p.i., o sea puñetera idea, y vaya con la deducción!), y que no entiendo, de las obras en ruso, más que los santos, como decía la analfabeta de casa cuando hojeaba y ojeaba los libros con láminas. Cuando con motivo del ajedrez tuve ocasión de tratar algunos rusos aprendí a duras penas a leer el alfabeto cirílico y las más esenciales abreviaturas del juego, pero aún así y todo ya ves tú que confundí la $\mathrm{r}$ con la $\mathrm{p}$, pero no fue por falta de atención, no sino error debido a la proximidad de ambas teclas. (El Balachov por Balashov fue un «lapsus machinae».)

Me habéis entristecido sobremanera, y no exagero, tú y Luciano al posponer vuestra visita a Palma para «la primavera, marzo o abril». Que largo me lo fiáis!... Aunque soy hombre que está, más que lleno, repleto de desánimos repentinos, que luego supero rápidamente, confío en que seguiré, entonces, tan ilusionado como ahora, o más si cabe, si el cuerpo aguanta y la situación económica lo permite, que también es factor que cuenta, ay!, por desgracia, en todo momento.

Estaba animado y decidido a saltar el charco y acompañarte a USA. Incluso había pedido al cónsul «usense» (¿por qué no ponemos en boga este término, mucho menos despectivo que «yanqui» y mucho más práctico que «estadounidense»?), gran amigo mío, que me diese todos los visados y permisos en regla. Pero el trabajo profesional y el «primum vivere» de siempre me lo tiene prohibido, por lo visto.

No vas errado ( $\sin$ hache) al barruntar que estoy algo así como en crisis «estrésica» (de «Stress»). Pero esto creo que me ocurre desde mi infancia y que no sé trabajar si no es a base de presentir que estoy haciendo un esfuerzo. Imagínate que de tener media jornada libre a la semana (aparte de los domingos por la tarde, en que impepinablemente estoy en casa o en la finca, así alternando) me hice socio de un club de ajedrez de Alcudia (a $50 \mathrm{~km}$ de Palma), sólo para verme obligado a jugar, en el torneo insular por equipos, una partida semanal. Y de momento no me quejo; llevo un solo empate y todo lo demás son victorias, lo que considerando que hacía más de diez años que no jugaba una sola partida de campeonato, es un gran éxito. A ver si todavía el amigo Criado de Val se va a atrever a desafiarme para darme el mate de Sajarov... Díselo, si lo ves. 
Gracias muchas por la localización del artículo de Balashov (esta vez correctamente escrito). Ocurrió que, de la fotocopia que saqué de tu ejemplar, yo me reservé las pp 278 y ss (que contienen las papeletas propiamente bibliográficas) para traducirlas yo mismo, lo que ya he hecho, a fuerza de paciencia, y di a un sobrino mío, gran políglota en ciernes, para que me tradujera el texto de los artículos generales, lo que aún no ha hecho; y claro, no me percaté de que el artículo de Balashov era el primero de ellos.

Voy a pedir el libro de Cherchi a Sánchez Cuesta o Miessner. Si no me lo consiguen, habrá que fotocopiarlo también.

Estuve, hace unas semanas, un día en Valencia, y pasé unas horas agradabilísimas con Vicente Gaos, y vi cómo ya está en estado avanzado la corrección de sus pruebas para la edición del Quijote. Va a haber, por lo visto, varias paridas de Quijotes, hogaño. Tanto bueno. Esto es señal evidente de cómo sigue inquietando al mundo cultural.

Voy a acabar porque hay que hacerlo algún momento y porque van a dar las nueve de la mañana y espero visitas en el despacho. Espero que me digas cómo te habrá ido en USA. Y mientras tanto recibe un fuerte abrazo de este quijoteril mallorquín, que lo soy.

Pepe

\section{Contestación de 11 de diciembre de 1977 [tarjeta postal]}

Es una tarjeta postal de Atenas escrita en Madrid a la vuelta de Estados Unidos, con el envío del Programa del Simposio cervantino celebrado en Fordham University, donde intervino D. Alberto. (Es de Atenas, el templo de Efestos (Teseión)

Madrid, 11-XII-77

Querido Pepe:

Ante todo, te deseo, de corazón, unas felicidades sin tasa, en la próxima Navidad; y un año 1978, a la medida del optimismo más entusiasta. He regresado de Nueva York esta misma mañana, mejor dicho esta madrugada, pues ayudaron mucho los vientos atlánticos (Dios se lo recompense); y contesto a tu carta del 23-XI, con el programa del Simposio cervantino de Fordham, para tu colección. Ahora descansaré ( ¿?) unos días con los exámenes fin de trimestre, y para fin de año saldré para Atenas, de que te ofrezco aquí un anticipo. Lo de América ha quedado francamente bien. Esperemos que la anunciada publicación no se demore con exceso, pues hay varios trabajos de gran mérito (yo diría que hasta cuatro, lo que es bastante para estas ocasiones). Por ahora, recibe un cordial abrazo de tu amigo.

Alberto 


\section{Carta decimoséptima: 13-XII-1977}

Es breve el texto, pero es muy interesante el envío dedicado (algo así como un autógrafo del traductor) de la «Cançó d' en Grisòstom» (D.Q., I, XIV) con las anotaciones que en su día llevará al «Prefaci del traductor». ¡Una joya bibliográfica-bibliofílica-científica! Véase pp. 154-160 de su edición de 2005.

Palma de Mallorca, 13 diciembre 1977.

Sr. D. Alberto Sánchez

Alcalá, 323

Madrid-27

Estimado Alberto:

Acabo de recibir tu anticipada postal, presagio de tus olímpicas andanzas, y el retrospectivo folleto de la «three-day conference», o como se diga, de la Fordham University: cosas ambas que no han hecho sino despertar mi envidia (pero de clase «sana» de la que habla Cervantes) y asegurar mi capacidad de confortable (a la fuerza) resignación. ¿Qué se le va a hacer? Aquí estoy yo con mi rutinario trabajo de cada día. A veces he llegado a creer que lo que movió a Don Quijote en busca de aventuras, no fue el extravío de su mente a causa de la indigestión de malas lecturas, no, sino su natural incapacidad en aceptar lo rutinario como empresa noble y santa. Puede que a mí me ocurra otro tanto.

Dentro de unos días mandaré al Consejo un paquete con varios obsequios para todos los amigos cervantistas de Madrid. Naturalmente, habrá uno para ti. Pero mi felicitación navideña quiero que sea expresamente más apropiada a nuestros comunes desvelos, y como no tengo costumbre, como otros, de pregonar mis escasos méritos de dilettante del cervantinismo, ni por otro lado, jamás se me ha ocurrido hacer imprimir pliegos sueltos ni demás memorándums, te mando, en su substitución, fotocopia de la traducción mallorquina de la "Canción de Grisóstomo», que forma parte de la mi traducción mallorquina de todo el Quijote, que, si Dios quiere, algún día publicaré, después de haberla rematado, claro.

Respecto de la cual he de advertirte que, debido al carácter festivo en extremo que para nosotros tiene nuestra parla común, el sentido de mi traducción, parejo con el del resto de la obra, abunda en expresiones con esta marcada tendencia festiva. Festiva, pero no cómica, no «payásica» para explicarme mejor. Espero que no se te escape ni una palabra de la traducción, aunque posiblemente algunos giros o expresiones sean exclusivamente de Mallorca.

Y con esto y lo que seguirá, felices fiestas, feliz año, y etc. Y dirás si el Partenón sigue donde siempre. Me lo dirás en enero, a tu vuelta, en que os espero, a ti y a Luciano, en Palma, como ya os dije.

Un abrazo

No hay respuesta. 


\section{Carta decimoctava: 17-XII-1978}

Lo más interesante de la última carta son los comentarios sobre su versión al mallorquín del Quijote y el retraso inevitable surgido por su quehacer. Habla de la enfermedad del común amigo. D. Miguel Bordoy, el coleccionista que tuvo a gala haber formado un museo cervantino. Asimismo escribe de Lois Carlos Pérez Castro (†), investigador del Consejo y gran amigo suyo y mío, del área de Clásicas.

Palma de Mallorca, 17 dic. 1978.

Sr. D. Alberto Sánchez

Alcalá, 323

Madrid-27

Mi querido amigo:

Mis felicitaciones navideñas van acompañadas, hogaño, y además de los votos y deseos más sinceros para que Dios os dé a todos salud, humor, buena compañía, etc., de una fotocopia de los versos preliminares de mi traducción mallorquina del Quijote, como antaño te mandé la referente a la canción de Grisóstomo. Está tomada la fotocopia de mi mecanoscrito, necesitado aún de muchos repasos y más correcciones hasta llegar al definitivo, y acompañada de la parte relativa a las anotaciones que, para un lector mallorquín especialmente, voy elaborando. Tengo ya terminados en su totalidad los 17 primeros capítulos de la primera parte y todos los 74 de la segunda. De los restantes capítulos (18 a 52 de DQ1) tengo solamente acabados algunos fragmentos y me falta todo el aparato de las anotaciones. Hubiese tenido la obra lista ya para una última corrección final y dispuesta para la imprenta a finales de noviembre, si varios reveses, todos al unísono, no se hubieran interpuesto. Seguramente nos veremos en Madrid, en la segunda quincena de enero, como acabo de decir por teléfono a Lois Pérez Castro, con quien acabo de tener una conferencia telefónica.

Nuestro amigo Bordoy (que recibió hace poco carta tuya, según me ha dicho) está enfermo de cuidado, aunque sospecho que él lo ignora. Durará lo que Dios quiera, desde luego, pero algunos conocidos suyos dicen que no mucho. Lo sentiría de veras porque es un buen amigo. Apenas sale de su casa.

A través de Lois os he mandado un pequeño obsequio de turrones de casa. He efectuado el envío de una sola vez a nombre de Lois y él os repartirá un paquete a cada uno. Me he limitado a los de la «pandilla» que más o menos habéis tenido relación conmigo.

Te escribo en domingo porque los días festivos no tengo ni medio minuto para mí. Y hoy estoy levantado de las cinco de la mañana.

Da recuerdos a todos mis compañeros del CSIC, a quienes no escribo directamente como he advertido a Lois. Y para ti un fuerte abrazo cervantinesco. 


\section{Contestación manuscrita de 21 de enero de 1978}

Comenta qué le ha parecido la versión al mallorquín de la Canción de Grisóstomo. Habla de su viaje a Grecia. Se muestra afligido en su deseo (compartido) por ofrecer cada vez mejor la revista editada precisamente gracias al Consejo.

Madrid, 21 de enero 1978

Sr. D. José M. ${ }^{\text {a }}$ Casasayas Truyols

Palma de Mallorca

Mi querido amigo:

A su debido tiempo llegó tu carta de felicitación navideña, del 13 de diciembre, acompañada del espléndido anticipo poemático de tu traducción del Quijote al mallorquín que he saboreado — paladeado - con el deleite del vino generoso. Aquí se puede repetir lo del licor añejo en odres nuevos. Tu «Cançó d'en Grisóstom» tiene, a la vez, empaque y registro vernáculo. Frente al Betis humanista, el acercamiento de tu versión «de Can Pastilla a l'Arenal» ofrece el calor de lo cercano. Lo que tal vez de evapora un poco en tus versos, sería la explicación del suicidio, ahorcándose, que resulta bastante clara en las estrofas V-VI del original. Debo felicitarte y congratularme entre los cervantistas, porque si en un texto de las dificultades de éste, lo has hecho con tanta dignidad, cabe esperar que en los diálogos tan sabrosos y espontáneos del caballero y el escudero, tu traducción ha de ser excelente.

Volví de mi viaje a Grecia verdaderamente entusiasmado. Me di cuenta de la capacidad de entusiasmo que me queda todavía. De vuelta me esperaban las últimas 150 págs. de las pruebas ajustadas del tomo XV de los ANALES. Me las he corregido pacientemente, pues de esta parte final del volumen una mitad había sido redactada por mí. Confiamos en que aparezca, por fin, el mes de febrero próximo. Te diré en confianza que Luciano García ha sido amonestado por los jefes administrativos de esta casa por haber excedido un tanto el número de páginas recomendado (con su natural incidencia en la factura de imprenta). Nos hemos acercado "peligrosamente» a las cuatrocientas páginas (exactamente son 386). No quiero ahora recordar que en otra ocasión (única) logramos rebasar las 500.

Supongo ya en tu poder la $1 .^{\mathrm{a}}$ circular del I Congreso cervantino de julio. No he conseguido hablar con Criado, desde el acto de Alcalá, porque siempre anda en viajes dentro y fuera de España. Mi amigo Allen, profesor de La Florida, me ha hecho enviar su nueva edición del Quijote, en dos tomos «negritos» de la Col. Cátedra (antigua Anaya). Mi primera impresión sobre los grabados, notas, introducción y bibliografía, es francamente buena. Espero ahora la de Castalia, preparada por Murillo y, para más tarde, la de Vicente Gaos, que supongo será la mejor.

En espera de tus noticias, te envía un buen abrazo. 


\section{El documento notarial cervantino}

José María lo canjeó por libros en Palma de Mallorca a un coleccionista no cervantino y corresponde en la fecha al día ocho de julio de 1593 en Sevilla. Es una carta de pago de Miguel Cervantes de Saavedra, criado del rey, a favor de Andrés de Cerio. Se puede consultar en Documentos de Miguel de Cervantes Saavedra de K. Sliwa ${ }^{1}$, quien remite a la edición conocida de Asensio y Toledo, mal transcrito en su texto no sabemos por qué al tenerlo presente. Cuando lo conocimos varios en el viaje a Palma de 1977 no estaba considerado como original. Creo recordar si quien lo consideró válido fue Manuel Sánchez Mariana, uno de los fundadores de la Asociación de Cervantistas en 1988, una autoridad indiscutible. Pasan los años y en el catálogo de la Casa de Subhastes de Barcelona para el 11 y 12 de marzo de 1998 (Libros, Manuscritos, Mapas y Obra gráfica) aparece el lote con número 166 y el comentario «Rarísimo documento autógrafo de Miguel de Cervantes (15471616)». Con un precio de salida de seis millones de pesetas y que alcanzó en la puja más de once millones de pesetas. Sin embargo la Junta de Andalucía inició trámites para reclamar el documento «que considera que procede de sus Archivos Notariales de Sevilla, de los que salió de manera irregular y de forma desconocida en fecha indeterminada» ${ }^{2}$. José María viajó a Sevilla y volvió contrariado al no haber podido consultar el legajo posible del que debía faltar. Pasó de nuevo el tiempo, él falleció en Palma. Después fui un día llamado por los hijos como perito por parte de ellos para informar en juicio a celebrar en un Juzgado palmesano. Recuerdo que vino conmigo Lois Carlos Pérez Castro $(\dagger)$ como testigo al haber conocido el documento en 1977. Hubo varias personas más que testificaron por carta cómo lo conocieron (no se tenía por original en aquella época), además de alguien más de Palma que sabía cómo llegó a José María el tal documento, una curiosidad de época tan sólo. El abogado de la familia fue un sobrino de José María, quien defendió la tesis del tiempo transcurrido para reclamarlo la Junta, anterior a la ley vigente. La representante del Archivo hispalense demostró en su informe la autenticidad documental. Al perder la sentencia la Junta, apeló a la Audiencia, donde volvió a perder. Reclamó ante el Tribunal Supremo, y este alto tribunal se ha inhibido por no ha lugar. El catálogo de la Casa de Subhastes de Barcelona ofrece una reproducción parcial muy buena del documento (el revés con la firma de Cervantes).

Este trabajo ha sido posible gracias a la comprensión y ayuda de varias personas. Deseo agradecer de nuevo a la familia de D. Alberto Sánchez, en

1. Pamplona. EUNSA. Anejos de RILCE, n. ${ }^{\circ} 31,1999,426$ pp.

2. El País, Madrid, 29-VI-1998, p. 36. 
especial a Marta Sánchez, el acceder a publicar parte de tan impresionante epistolario. Pues este nos revela cómo pensaron dos cervantistas muy conocidos, y cómo llegaron a compenetrarse en su vocación idealista de admirar e interpretar a Cervantes. Además percibo personalmente una época ya finalizada por el cambio generacional y el adelanto técnico en la comunicación. Aunque sigo siendo bibliófilo y me gusta escribir de manera tradicional. Asimismo agradezco a mi amiga y colega, la Dra. Alicia Villar, los consejos para asesorarme en las dudas con la correspondencia, algo delicado al estar unido la parte científica con la personal. Agradecimiento extensible a Abraham Madroñal y asimismo a la familia de José María, de manera especial a Margarita Casasayas. Y por último a la Asociación de Cervantistas, a la que me honra pertenecer desde sus orígenes, y a su actual presidente, el prof. José Montero Reguera, quien ha hecho posible enriquecer el contenido epistolar de D. Alberto. Todos ellos han hecho posible la publicación actual. 